\title{
A GROTESQUERIE PARISIENSE: TRAÇOS DO INSÓLITO NA NARRATIVA POLICIAL DE EDGAR ALLAN POE
}

Vinícius Santos Loureiro (UFRJ)

Recebido em 10 mai 2020. Vinícius Santos Loureiro é Doutorando em Aprovado em 19 jun 2020. Literaturas Hispânicas na Universidade Federal do Rio de Janeiro, onde estuda comparativamente as obras de Edgar Allan Poe e Jorge Luis Borges, com ênfase no desenvolvimento do insólito ficcional nos contos de ambos autores. É membro do Projeto Fortuna, vinculado ao PPG em Ciência da Literatura da Universidade Federal do Rio de Janeiro, sendo organizador de duas edições (2018/2019) da Edgariana - Encontro de Pesquisadores de Edgar Allan Poe, evento realizado na Faculdade de Letras da referida Universidade.

Lattes: http://lattes.cnpq.br/5639914117694209

E-mail: loureiro.vn@gmail.com

ORCID iD: https://orcid.org/0000-0002-9329-898X

Resumo: Edgar Allan Poe foi o criador de uma obra cuja grandeza artística é proporcional à heterogeneidade que a compõe. Fora do mérito de se tratar de um dos inventores da narrativa detetivesca, o autor legou à posteridade uma série de contos, poemas, ensaios e correspondências, tangendo desde os temas clássicos da literatura fantástica até uma produção humorística e tantos exemplos de ficção à moda especulativa de caráter filosófico. Por tanta variedade, não foram poucas 
as tentativas de segmentar sua obra conforme seus temas. Em meio a esse esforço de classificação, tornou-se habitual que se considerasse que os contos de raciocínio, grupo que reuniria os três relatos do detetive $C$. Auguste Dupin e alguns outros afins, estaria destacado dos demais. A justificativa passa, em alguma medida, pela defesa do contraste provocado pela aura de esclarecimento que permeia o conto policial, reflexo de um mundo desejoso de se organizar pelo conhecimento e pelos desenvolvimentos tecnológicos, contra os impulsos nervosos herdados pela influência gótica, influindo especialmente sobre seus contos de horror. Entretanto, a narrativa que perpassa os acontecimentos que circundam o assassinato brutal de mãe e filha em uma Paris em plena ebulição ressoa em outros contos do autor, seja pela criação de atmosfera, seja pelas impressões comunicadas pelos respectivos narradores-testemunhas. O objetivo deste artigo será o de refletir a respeito das semelhanças entre a narrativa detetivesca de Edgar Allan Poe, a partir do conto "Os assassinatos na rua Morgue", e algumas de suas narrativas fantásticas. Palavras-chave: conto fantástico; romance policial; gótico; teoria do conto.

Abstract: Edgar Allan Poe was the creator of a work which artistic greatness is proportional to its heterogeneity. Besides the merit of being one of the inventors of detective narrative, the author conveyed a series of short stories, poems, essays, and correspondence, approaching from classic fantastic themes from humoristic productions and many examples of speculative-like fiction of philosophical character. For such a variety, there were many attempts to segment his work according to its themes. Among this classification effort, it has become usual to consider that ratiocination tales, group that would gather the three C. Auguste Dupin stories and some others related, would be detached 
from the rest. To some extent, this explanation approaches the argument of the contrast caused by the enlightenment aura that permeates detective fiction, reflecting a world willing to to organize itself through knowledge and technological developments, against the nervous impulses inherited from gothic influence, mainly affecting horror stories. However, the narrative that runs through the events surrounding the brutal murder of mother and daughter in a broad-boiling Paris resonates in other Poe stories, either by creation of atmosphere or impressions communicated by respective narrator-witnesses. The purpose of this article is to ponder on the similarities between Poe's detective fiction, analyzing "The murders in Rue Morgue", and some of his fantastic stories.

Keywords: fantastic short story; detective fiction; gothic; short story theory.

O aspecto fragmentado da obra de Edgar Allan Poe se mostra recorrentemente como porta de entrada para todo tipo de investigação acerca de sua produção artística. O fato, motivado tanto por sua morte precoce aos quarenta anos quanto por toda a sorte de adversidade que o autor enfrentou em seus breves anos, é o resultado de uma vida dedicada ao trabalho em periódicos onde seus escritos invariavelmente vinham ao mundo - e dos poucos volumes compilados que pôde editar. A perspectiva é agravada após o caso Griswold, cuja postura injuriosa à figura de Poe, estabelecendo a caricatura de toxicômano romântico que o acompanhou post mortem por décadas, voltou parte da atenção da crítica especializada ao aspecto nervoso do autor.

Uma das maiores complexidades provocadas por este fracionamento dá-se pela dificuldade inerente de se abarcar a 
pluralidade de sua obra. Fora do escopo de ter escrito em prosa e verso, ficção e crítica, Poe é o autor de textos cuja motivação e resultado parecem se comunicar com interlocutores plenamente singulares, isto é, além da produção mais celebrada de contos fantásticos, Poe navegou pelas águas ainda desbravadas do romance policial, voltando-se por vezes ao escárnio e ao tom grotesco percebidos em sua obra, em outras pulsando com a semente de uma faux ficção científica ou especulativa.

A coexistência de vieses tão ímpares dentro de uma obra parcamente reunida provocou, tanto em termos de crítica quanto de formação de uma figura dentro do cânone, a ocorrência de tentativas de se estabelecer de uma forma ou outra uma genealogia peculiar a cada um desses subgêneros. À contraluz, parece ser a relação entre o insólito e o detetivesco o maior ponto de distinção dentro da obra de Edgar Allan Poe. Se, de alguma forma, parte da crítica admite que ambos compartilham da mesma origem, outra parte mantém a distinção ainda hoje. Todorov, por exemplo, em meio aos demais problemas de seus escritos introdutórios ao estudo do fantástico, afirma que

esta proximidade não é um produto do acaso; escreve-se aliás frequentemente que as histórias policiais tomaram o lugar das histórias de fantasmas. Precisemos a natureza desta relação. O romance policial de mistério, onde se procura descobrir a identidade do culpado, é construído da seguinte maneira: há por um lado muitas soluções fáceis, à primeira vista tentadoras, mas que se revelam falsas uma após outra; por outro lado, há uma solução inteiramente inverossímil, à qual só se chegará no fim, e que se revelará a única verdadeira. Pode-se perceber já o que aproxima o 
romance policial do conto fantástico. Lembremos das definições de Soloviov e de James: a narrativa fantástica comporta também duas soluções, uma verossímil e sobrenatural, outra, inverossímil e racional. Basta, portanto, que esta solução seja, no romance policial, difícil de encontrar chegando mesmo a 'desafiar a razão', e estamos prontos a aceitar a existência do sobrenatural de preferência à ausência de qualquer explicação. (2010, p.55)

Por outro lado, ao passo que os contos de medo, imaginação e morte - como se habituou genericamente a chamar os contos de temática insólita - descendem do passadismo lúgubre do romance gótico, descendo às profundezas do desespero de um mundo que falha ao se organizar pelo racionalismo, o romance policial se vangloria de determinado grau de racionalidade proveniente das revoluções tecnológicas e científicas surgidas no final do século XVIII, determinando a ausência de espaço para o sobrenatural na configuração das grandes metrópoles europeias, que começam a tomar as formas atuais nesta altura. Enquanto o fantástico conserva seu interesse no ausente aos sentidos, variando por vezes entre os limites da experiência humana e um abstracionismo puramente especulativo, a narrativa policial se revela um subgênero fundamentalmente contemporâneo de si mesmo, refletindo a mudança de paradigmas quanto à ordem social (PORTILHO, 2009, p.36).

De fato, o próprio Edgar Allan Poe utilizava o termo ratiocination para referir-se a este tipo de conto, revelando sua tendência à temática mais esclarecida, em oposição à prosa que se nutre das vertentes do grotesco e do arabesco, também por sua denominação. Desta forma, tornou-se convencional atribuir a 
estas duas vertentes de sua obra um pertencimento a linhagens totalmente distintas que guardassem pouca ou nenhuma relação entre si, aproximando-se mais por ocasião de ambos os subgêneros estarem ligados à literatura de massas do que por alguma justificativa de ordem intrinsicamente literária. Contudo, essa aparente falta de proximidade que ambos os gêneros parecem nutrir por uma questão de metodologia de composição mostrase incipiente conforme é visto que, desde sua gênese, as duas categorias têm diversas similaridades, chegando ao ponto de uma se servir da natureza da outra para o próprio estabelecimento. Portanto, o objetivo deste artigo será discutir a relação entre a narrativa fantástica e a história de detetive, tomando como exemplo "Os assassinatos na rua Morgue".

Publicado em 1841, "Os assassinatos na rua Morgue" é o primeiro dos três contos de Edgar Allan Poe tendo como personagem principal o detetive C. Auguste Dupin. Neste conto, o narrador apresenta seu amigo Auguste Dupin, sujeito de altíssima capacidade analítica, uma espécie de inteligência sem par na cidade de Paris, cenário para o conto. A atenção dos dois é tomada por uma notícia de jornal que relata a morte terrível de uma mãe e sua filha dentro da própria casa sob circunstâncias terríveis. Fora o caráter sangrento do crime, determinadas nuances de sua execução tornam sua resolução ainda mais complexa, aparentando mesmo ser impossível a descoberta de sua autoria. Levado pela ineficiência da polícia para a resolução do crime a partir do estudo da cena e dos relatos das testemunhas que entraram no local após os gritos acordarem todos na madrugada do ocorrido, Dupin resolve agir por conta própria para buscar a resolução do crime. Através da 
aplicação de seus próprios métodos de análise, o "detetive" acaba por solucionar o caso e desfazer as acusações injustas contra um homem. De todas as possibilidades que nos chamam a atenção para a discussão desse conto em particular, iniciamos pela estranheza dos fatos que o compõem.

Portanto, entramos nos assassinatos precisamente pela rua Morgue. A rua criada por Poe para ser o cenário da ação principal deste conto já antecipa parte da questão que suscita, não ainda por seu nome, mas pelo modo como se chega a ela. É comum entre os comentadores de Poe que se destaque a Paris irreal que é apresentada pelo narrador desse conto em particular. Ainda que as referências gerais à capital francesa sejam de fato reais, a disposição geográfica dos pontos exibidos na narrativa ignora as distâncias de fato entre esses mesmos pontos. A Paris de Dupin espelha-se na Paris factual, mas é uma cópia quebrada.

Many of Poe's inaccuracies - a few of them flagrant errors - in details of his French setting have been criticized. Forgues [...] noted some that would startle Parisian readers but conceded that Poe, in giving his details for verisimilitude, was writing primarily for Americans and that tales of the very unusual have frequently been laid in distant lands. Charles Baudelaire, sympathetic to Poe, did not let the "errors" bother him, but remarked in a footnote to his translation, "Do I need to point out that Edgar Poe never came to Paris?"1 (MABBOTT, 1978, p.569)

1 Várias das imprecisões de Poe - algumas delas erros flagrantes - quanto a detalhes do cenário francês foram criticadas. Forgues [...] observou algumas que teriam surpreendido os leitores parisienses, mas reconheceu que, detalhando em prol de verossimilhança, escrevia primariamente para americanos e que contos estranhos com frequência se passavam em terras distantes. Charles Baudelaire, simpático a Poe, não se incomodou com os "erros", mas observou em uma nota de rodapé a sua tradução, "Preciso apontar que Edgar Poe nunca veio a Paris?” (Tradução nossa) 
Por outro lado, a quebra da representação real da cidade não nos causa nenhum prejuízo enquanto leitores; pelo contrário, o esforço de alusão à Paris nos oferece uma perspectiva extremamente interessante da estrutura do relato, pois deixa transparecer a criação de atmosfera inerente à elaboração de um conto fantástico. Partindo da consideração de um efeito, recordando do ensaio "A filosofia da composição", o autor faz com que a narrativa se dê em meio a um local propício para que os acontecimentos tenham maior nível de verossimilhança, tornando o leitor mais propenso às nuances da história (POE, 2019, p.58). O crime horrendo ganha potência ao ser alocado em uma metrópole em plena expansão, à noite, testemunhado por homens e mulheres de diferentes origens culturais e étnicas. Assim como em outro conto célebre de sua autoria, o criminoso está invisível na multidão.

Ainda a respeito da construção de uma atmosfera, interessante observar como o léxico utilizado para apresentar os diferentes vieses do crime colabora para essa proposta. A rua Morgue, cenário do crime, é ficcional. Na ausência de uma indicação factual a que se referir, o texto original projeta uma preparação à cena mortuária, uma vez que o termo morgue corresponde em língua inglesa a necrotério ${ }^{2}$. De forma clara, ação e cenário compartilham da mesma natureza, ambos sob o signo fúnebre que, recuperando a linha temporal da narrativa, parece ascender do subterrâneo à superfície da linguagem: a morte jazia em repouso no nome e, posteriormente, irrompe na dinâmica dos acontecimentos. A este respeito, Luciana Colucci comenta:

2 O substantivo morgue também está presente nas línguas portuguesa e francesa (o cenário do conto é Paris); contudo, ao menos em nosso caso, sua utilização não é recorrente. 
Atentemos para a escolha lexical temática e formal: melancolia, grotesca, casinha, ruínas, superstições, solitários. Já temos aqui, logo no início do conto, a configuração da espacialidade gótica que Poe herda de sua predileção pela tradição heráldica inglesa, mas, no lugar do castelo medieval inglês, temos a casa que, com suas nuances antropomórficas e supersticiosas, revela um lugar ideal para a instauração do suspense. Ademais, essa situação já suscita a relação que ora nos interessa: a presença da espacialidade gótica nos contos policiais de Poe, com seus ambientes e personagens peculiares. (2014, p.148)

Similarmente, as únicas palavras que as testemunhas puderam identificar em meios aos gritos de pavor das duas vítimas foram sacré, diable e mon Dieu ${ }^{3}$ (POE, 2017, p.130). A estreita relação entre o conto de raciocínio e o conto fantástico é ressaltada mais uma vez ao percebermos que o léxico insólito, que é parte fundamental da cena de horror, está presente aqui. Isso tudo, somado ao caráter também insólito do assassinato em quarto fechado, permite que a intepretação questione a naturalidade dos fatos. Não seria nenhum absurdo que o leitor imaginasse que as palavras ditas fora de contexto se referissem a uma espécie de ritual, por exemplo, ou que o assassino fosse de natureza tal que o permitisse adentrar e sair de recintos sem abrir portas ou janelas. À frente, o crime é primeiramente apresentado ao leitor através de uma notícia de jornal, cujo título nada desinteressado é "Assassinatos Bizarros" (POE, 2017, p.126). Além disso, o próprio Dupin afirma ao longo da narrativa que o crime e as circunstâncias peculiares ao estado em que os corpos foram encontrados

3 No original, em francês, sagrado, diabo e meu Deus. 
se tratam de "uma grotesquerie de horror alheia a qualquer parâmetro de humanidade" (POE, 2017. p.145).

Dessa forma, torna-se possível perceber que o autor não deixa de recorrer aos temas do macabro e do absurdo, mesmo nos contos de raciocínio. De fato, a presença de uma série de elementos estruturantes do insólito estão presentes em "Os assassinatos na rua Morgue": a escolha vocabular, a construção de uma atmosfera propícia para a ação que vem a ser narrada e a dubiedade com relação aos acontecimentos estão presentes na própria estrutura desse conto de raciocínio.

Contudo, importante atentar para a recuperação da teoria do fantástico, ressaltando que o recurso utilizado por Poe é mais propenso à criação de atmosfera que a apresentação de um cenário, funcionando somente como pano de fundo para a ação. Benjamin Franklin Fisher aponta para o pioneirismo do autor dentro da literatura estadunidense, não apenas por essas cidades possuírem o aspecto de "hotbeds of insanitary conditions, violence and crime [...] too accelerated for comfortable, pleasant living ${ }^{4 \prime \prime}(2008$, p.21) - o que justificaria seu emprego para o enredo deste conto -, mas como verdadeiros pontos de interesse para personagens e leitores. De forma semelhante, Luciana Colucci aponta para o espaço elevado à importância de personagem (2014, p.147), não sendo subjugado por qualquer nível hierárquico frente a outros recursos:

Ao manter a mesma conjunção entre espaço/ personagem observada em Os crimes na Rua Morgue, observa-se que Poe, ao partir de seu 4 "incubadoras de condições insalubres, violência e crime [...] muito aceleradas para uma vida confortável e agradável". (tradução nossa) 
próprio conceito de efeito e fazer literário, rejeita a hipótese de que "uma tese [...] é sugerida por um incidente do dia". Com um rígido controle sobre a escritura e a rejeição de composição ao acaso ou à intuição, o escritor insere personagens que interagem com o ambiente, reforçando sobremaneira o efeito por meio de um tom lúgubre e assustador, pois, como é possível ler no início de Marie Rogêt, "[p]oucas pessoas há, mesmo entre os pensadores mais serenos, que não tenham sido alguma vezes assustadas por uma vaga, e contudo arrepiante, semicrença no sobrenatural". (2014, p.150)

Até por conta desta construção em prol de um efeito, a atmosfera de horror projetada sobretudo pela brutalidade do crime não se desfaz ao longo do conto. O posterior "apaziguamento" do sentido insólito provocado pela resolução do caso - mesmo do modo grotesco que é o assassinato realizado pelo orangotango atrapalhado - é proporcional ao pensamento todoroviano acerca da definição do fantástico "puro". Recordando em linhas breves, Todorov defende que o fantástico não se trata precisamente de um gênero, mas um entrelugar projetado pela hesitação do leitor ou mesmo da personagem quanto à verificação da ocorrência de um episódio que ponha em dúvida os limites das leis naturais; ao término do texto, caso houvesse esclarecimento quanto aos fatos, o fantástico deixaria de existir, dando lugar a outro gênero: para o autor, a experiência do fantástico, antes de tudo, pertence à ordem do lógico ou cognitivo. Portanto, o desaparecimento da sensação incômoda que acompanha o relato sobrenatural, em tese garantido pela racionalidade do detetive, é também um elogio da chave lógica e 
da perspectiva cognitiva que o leitor e as personagens devem compartilhar ao término do texto. Em ambos os casos, para o insólito e para o romance policial, a literatura sempre está em débito com outras dimensões do conhecimento, que parecem ter prioridade frente a seu próprio corpo textual. Em suma, para esta linha de pensamento, a literatura é muitas outras coisas antes de ser ficção.

Com relação ao caráter absurdo da história, importante também ressaltar a presença do estranho humor de Poe - ou suas tentativas quase fracassadas de o produzir. Julio Cortázar, que traduziu e comentou genialmente a obra de Poe, discorre sobre os problemas provenientes de seu estranho senso de humor, cuja motivação por vezes aparenta ser indecifrável, mas invariavelmente produz cenas ambíguas, carregando a sátira e o escárnio de tons diametralmente opostos a qualquer sentido tradicional de humor. De fato, algumas passagens do conto remetem a este tipo de elaboração: a figura de um sapateiro de baixa estatura que se fantasia de ator trágico ${ }^{5}$, a reação boquiaberta do narrador ao ter sua linha de pensamento metodicamente analisada por Dupin e a humilhação submetida ao policial após Dupin anunciar a solução do caso guardam uma comicidade, mas jamais distanciada de alguma forma de desprezo. No ponto mais alto da narrativa, é revelado ao leitor que os assassinatos foram cometidos por um orangotango à solta, motivado menos por uma ferocidade animalesca do que pela ingenuidade irracional de repetir os gestos que seu domador

5 A carnavalização plena, apontando para a representação encenada da inversão dos valores, ou, em grau menor, a convivência do gozo e da morte são temas recorrentes na obra de Poe. São exemplos desta tendência "O barril de amontillado", "O baile da Morte Vermelha" e "Hop-Frog". 
executava diariamente ao se barbear em frente ao espelho, cena que poderia observar pelo buraco da fechadura de seu refúgio. A resolução de um crime bárbaro se mostra como uma comédia de erros na qual a decapitação de duas vítimas são a consequência de uma cena circense, variando bruscamente do infernal ao jocoso. De fato, o próprio Cortázar afirma que conforme "Poe incorre no que ele crê humor, [...] deriva imediatamente para o macabro" (2006, p.110), ressaltando como os dois polos, o riso e a morte, andam sempre próximos em sua obra, de forma tão caricatural como uma gargalhada diabólica.

Voltadas as atenções agora para a figura de Auguste Dupin, é possível continuar a estabelecer correspondências entre a narrativa policial e os contos fantásticos, isto porque o personagem também guarda similaridades com outros da obra de Poe, espelhando uma série de traços comuns ao gótico. Ainda que celebrado intratextualmente pelo narrador, pragmaticamente pela crítica - por sua altíssima capacidade intelectual, Dupin é apresentado como um sujeito decadente, mal integrado à sociedade e a seus códigos, recluso na intimidade de um abrigo onde pode se dar livremente ao próprio prazer. Talvez a comparação mais apropriada seja entre o francês e Roderick Usher, personagem central do conto "A queda da casa de Usher", comparação que ganha força a ponto de ser possível afirmar que Dupin é duplo de Usher. Para começar, tratam-se dois sujeitos decadentes que se enclausuram em suas próprias moradas, como "a representação do decadentista e da predileção poeana pela configuração de ente ficcional sob os moldes do dândi" (COLUCCI, 2014, p.151). No conto, lê-se: 
Pude alugar e decorar um lugar que atendia à melancolia fantástica de nosso temperamento, uma grotesca mansão alquebrada pelo tempo, há muito abandonada por conta de superstições que não quisemos apurar, equilibrando-se parcamente em uma área reservada e desolada do Faubourg St. Germain. Se a rotina de nossa vida neste local viesse a ser conhecida pelo mundo, teríamos sido tachados de loucos - embora, talvez, loucos inofensivos. Nossa reclusão era total. Não admitíamos visitas. De fato, a localidade do refúgio foi mantida em segredo, e meus antigos companheiros nada sabiam a respeito dela; quanto a Dupin, há muito deixara de conhecer e ser conhecida em Paris. Eu era a testemunha solitária de sua existência, e ele, da minha. (POE, 2017, p.126)

Ainda, a correspondência é estabelecida conforme ambos são representados como homens de elevada cultura e educação estética, mas em contrapartida dotados de um nível de hipersensibilidade que provoca a necessidade de afastamento: Dupin só sai de casa à noite; Roderick, mais radicalmente, jamais deixa seus aposentos. Tanto o interior da casa de Usher quando do apartamento de Dupin são cenários de experiências sensoriais agudas, necessárias para o abrandamento de intelectos tão desenvolvidos.

Era uma extravagância da parte de meu amigo (que outro termo posso usar?) ser enamorado pela Noite; e a essa bizarrice, assim como a todas as outras, aderi sem protestar, entregando-me aos seus loucos capricho com total abandono. A divindade noturna não podia permanecer conosco o tempo todo, mas era possível emular sua presença. Aos primeiros raios da manhã, fechávamos todas as estropiadas venezianas da casa, acendendo um 
par de círios que, exalando um intenso perfume, filtravam apenas os raios mais débeis e sinistros. Com o auxílio dos círios, ocupávamos nossas almas com sonhos - lendo, escrevendo, conversando, até que o relógio acusasse o advento da escuridão real. (POE, 2017, p.121-122)

Outro paralelo a ser traçado é entre Dupin e o narrador do conto "O coração delator". Em mais de uma ocasião, o detetive é caracterizado por determinada perda de seu tino, como se operasse entre a iluminação e a insanidade. Guardadas as devidas proporções - além da presunção de inocência de Dupin ao ser comparado com o assassino do outro conto -, ambos os narradores tem capacidades de detecção avantajadas um quanto ao intelecto, o outro quanto aos sentidos - e suas justificativas para o empreendimento das respectivas ações não está de imediato claro.

Nesses momentos [de análise], a postura de Dupin era fria e abstrata, os olhos pareciam vazios de expressão e a voz, normalmente um tenor encorpado, erguia-se em um timbre trêmulo que poderia parecer petulante, não fosse a intencionalidade e a distinção de sua fala. Observando-o nesse estado, eu muitas vezes ponderava acerca da velha filosofia da alma bipartida e entretinha-me com a fantasia de que havia dois Dupins - o criativo e o investigador. (POE, 2017, p.122)

Do mesmo modo, ao lermos que sua fala era direcionada "a mim, mas a voz, embora de modo algum alta, tinha a entonação que costumamos empregar quando nosso interlocutor está bem longe. Os olhos, vazios de expressão, fitavam apenas a parede." 
(p.137), recordamos quase imediatamente desse outro narrador que performa entre a loucura e uma sanidade iluminada, capaz de ouvir coisas no céu e no inferno. Outros ecos menores podem ser percebidos no quase transe intelectual de Dupin e no recuperar de consciência de outros homens um pouco menos afortunados como o narrador de "Berenice" e o de "O demônio da perversidade". De fato, os contos mencionados pouco têm em comum - mesmo que desconsiderássemos o conto policial. O que se percebe aqui é uma tipificação desse personagem edgariano, algumas vezes narrador, outras mero personagem, do qual pouco se pode extrair a partir de uma perspectiva confiável. Isso, contudo, corrobora para a dificuldade de se considerar a gama de similaridades levantadas como coincidência.

Ainda que estes dois primeiros pontos tomados para análise possuam significativa relevância para a discussão que aqui se pretende, ambos não abordam exatamente o cerne da questão dos gêneros: primeiro, a similaridade apontada quanto à escolha lexical, a semelhança temática e, consequentemente, a criação de atmosfera apenas indicam uma correspondência de recurso, que poderia, inclusive, ser com legitimidade justificada por uma série de argumentos não-literários, abordando mais a superfície da estilística que a noção estética; segundo, os comentários tecidos a respeito das personagens são relevantes para algum grau de desconstrução do lugar-comum, mas são mais surpreendentes por ocasião de uma quebra de expectativa que, se não devidamente observada, pode se converter em juízo moral. Desta forma, os dois tópicos, além da pertinência para a dinâmica dos estudos comparativos, são indicadores da 
manifestação de outra ordem significância que, esta sim, toca o âmago do romance policial.

O ponto do qual falamos se refere às capacidades analíticas de Dupin, não por sua eficácia, mas por suas motivações. À parte de qualquer justificativa que conduza o personagem para dentro da investigação - uma vez que o crime não resvala de forma alguma em sua vida, fato agravado pelo afastamento em relação ao cotidiano parisiense -, o investigador parece a priori movido por uma agência internalizada de deleite, revelando que a questão central de seu método é o prazer. Logo no início do conto, lemos que

As faculdades mentais referidas como analíticas, sabemos que, entre outras coisas, elas constituem, para quem as possui em grau extraordinário, uma fonte do mais vívido prazer. Assim como o homem forte exulta sua capacidade física, deleitando-se com as atividades nas quais possa exercitar seus músculos, o analista aprecia com entusiasmo as atividades morais capazes de desembaraçar a mente. Ele se regozija até mesmo das ocupações mais triviais que facultam o uso de seu talento. (POE, 2017, p.117)

Este elogio à inteligência se desloca rapidamente na direção do comentário pessoal, ao passo que o narrador afirma que "era com afã que Dupin parecia deliciar-se com esse exercício - ou em sua exibição" (POE, 2017, p.122). O ápice de suas faculdades mentais, quando aplicadas, constitui uma espécie de erotismo narcisista conforme percebemos que ele desempenha tais métodos pelo prazer obtido na contemplação das próprias capacidades intelectuais e do resultado de sua atividade. 
Ao contrário dos primeiros pontos comentados, essa questão de uma busca irrefreável pelo prazer representa uma leve atribulação, podendo instigar uma elaboração quanto à validade da narrativa policial edgariana para a constituição de um gênero como tal. Primeiramente, quanto a motivação prática: de fato, Carla Portilho (2009) aponta para um contexto histórico da atuação de detetives anteriores à de Dupin, movidos por motivos pecuniários ou pela obtenção de outros tipos de vantagens, mas, neste caso, a ausência de elo entre o investigador e a cena é ressaltada conforme relembramos que, como já mencionado, Dupin portase como uma espécie de exilado da vida social de Paris, não por uma má interpretação de seus códigos - o que configuraria, se contemporâneo, o comportamento de um weirdo mal integrado ao meio -, mas por um total desinteresse. A convocação ouvida tão-somente por seus ouvidos extremamente sensíveis é potente o bastante para que essa reclusão seja interrompida e ele tenha que, mesmo de forma breve, retornar ao convívio de seus pares para adentrar no íntimo de uma comunidade da qual não logra extrair qualquer usufruto. Depois, essa jornada de regozijo deve, de maneira anti-humanista, passar quase que literalmente por sobre os corpos ainda quentes das duas vítimas. $O$ detalhe que nos leva a perceber a situação por essa perspectiva surge, no âmbito da apresentação das circunstâncias horrendas dos assassinatos, a exibição sem pudor do que foi feito e de como foram encontrados os dois corpos no apartamento. Ao ter acesso a esses detalhes, Dupin compreende sua gravidade - corroborando que está consciente do grau diabólico da cena -, chegando a dizer que se trata de uma grotesquerie, de um grotesco quase pendendo aos 
extremos de uma teatralidade. Ainda assim, pelo modo como o desenvolvimento da narrativa deixa entrever, o protagonismo da cena investigativa é o próprio detetive, relegando as mortes à importância de um interessantíssimo pano de fundo para que o jogo dupiniano possa ocorrer. Em verdade, a pedra-de-toque na rua Morgue não se trata da violência cometida, mas a dificuldade de estabelecimento de uma verdade que justifique a sequência de fatos, demandando um grande poder cognitivo para que se revele. Os corpos de Madame e Mademoiselle L'Espanaye, destituídos de qualquer humanidade, transfiguram-se em peões no grande tabuleiro sobre o qual Dupin se compraz.

Desse modo, evidencia-se que o objetivo da investigação e da própria aplicação dos métodos desse proto-detetive do conto de Edgar Allan Poe tem fim em si mesmo. O motivo da investigação é o próprio percurso, o gesto de saciar-se pelo próprio desejo de saber a verdade a respeito do caso. De fato, após a confissão do dono do animal, o relato de Dupin à polícia tem o singelo intuito de livrar da prisão uma pessoa inocente e, como dito anteriormente, exibir a superioridade de seus métodos. Inevitável que esta discussão atraia a seu centro o questionamento quanto à capacidade intelectual do investigador, de certa forma, ser subjugada a um exercício menor: simultaneamente à sua instrumentalização - demonstrando como pode ser aberta uma senda em meio à escuridão dos mistérios mundanos pelo vigor da racionalidade transformada em prática -, a aplicação destas mesmas práticas tem seus efeitos ambicionados em um retorno ao indivíduo que, no caso de Dupin, nutre-se de um desespero mundano para saciarse na desproporção de sua alcova suburbana. 
Antes de dar esta discussão como finalizada, apenas para não deixar pontas soltas, talvez seja prudente esclarecer que o presente artigo não busca, de forma alguma, apresentar a acusação infundada que a obra de Poe seja contrária a qualquer nível de intelectualismo - ainda mais após o último aspecto ressaltado. É evidente que Poe preza pelas possibilidades que o conhecimento e a utilização das capacidades cognitivas oferecem, considerando que o próprio autor demonstra, tanto na ficção quanto na crítica, grande apreço pelos desenvolvimentos científicos e pela organização mental dos estímulos nervosos que herda dos autores românticos.

The technological components of the expeditions also aroused curiosity, though Poe was not always accurate in presenting such material. "MS. Found in a Bottle" and "A Descent into the Maelstrom" present details about sailing vessels, and the narrator in "A Descent" gives a scientific explanation for the motion of the whirlpool. Pym's sometimes extended accounts of what purports to be factual information, "The Cask of Amontillado" and "Hop-Frog," essays like "Street Paving," and even Poe's cryptographic writings, display his familiarity with other technological matters. He also understood printing processes. Architectural construction and home decor also appear in works such as "Metzengerstein," "The Raven," "The Murders in the Rue Morgue," "The Purloined Letter," "The Fall of the House of Usher," "The Duc de L'Omelette," "The Pit and the Pendulum," "The Philosophy of Furniture" and "The Black Cat." Ballistics are used to identify the murderer in "Thou Art the Man." ${ }^{16}$ (FISHER, 2008, p.23)

6 Os componentes tecnológicos das expedições também provocavam curiosidade, ainda que Poe nem sempre fosse preciso ao apresentar esse material. "Manuscrito encontrado em uma garrafa" e "Uma descida ao Maelstrom" apresentam detalhes sobre embarcações de viagem, e o narrador da última fornece uma explicação científica para o movimento do 
Por outro lado, é também justo que se destaque que, independente dos limites quase infinitos das faculdades mentais de Dupin, o método analítico que desempenha não é propositivo: considerando que de fato existe uma linhagem pura dos contos de raciocínio, sorvendo da influência do início da modernidade, de uma nova organização do mundo - enfaticamente urbano - e da convivência com novas tecnologias como forma de desenvolvimento da sociedade, a representação da existência terrena de uma intensificada capacidade analítica do sujeito cuja investigação não leva a resultados práticos caminha em sentido diametralmente contrário. Essa inteligência instrumentalizada, grande totem da narrativa policialesca, desacompanha o próprio zeitgeist do qual se supõe que é originada.

Por esse viés, torna-se quase cômico que se vislumbre através dessa narrativa que os grandes desenvolvimentos da humanidade pós-lluminismo não sejam coletivos ou minimamente voltados para uma espécie de aparato coletivo que de fato possa fazer uso desses avanços. O que vemos, por outro lado, é a solidão acentuada de um sujeito que, em posse do mais precioso aparelho cognitivo, vive em isolamento, em meio ao luxo de livros e velas aromáticas, resolvendo casos somente por prazer e representando, por fim, a própria falência das instituições urbanas, como visto em sua superioridade em relação aos investigadores da polícia parisiense.

redemoinho. Pym, por vezes, deu explicações extensas sobre o que alegava ser informações reais. "O barril de amontillado" e "Hop-Frog", ensaios como "Pavimentação Viária" e mesmo os escritos de Poe sobre criptografia revelam sua familiarização com outras questões tecnológicas. Ele também entendia de processos de impressão. Construção arquitetônica e decoração de casa também aparecem em sua obra, como "Metzengerstein", "O corvo", "Os assassinatos na rua Morgue", "A carta roubada", "A queda da casa de Usher", "O Duque de L’Omelette", "O poço e o pêndulo", "A filosofia do mobiliário" e "O gato preto". Balística é utilizada para identificar o assassino em "Tu és o homem". 
Ainda assim, esse conto não constituiria uma distinção dentro da obra de Edgar Allan Poe. Sendo possível a compilação de "narrativas de inteligência" ao modo de "Os assassinatos na rua Morgue" dentro da obra de Poe, analogamente à citação de Benjamin F. Fisher supracitada, atentamos para contos que trazem desde um amplo conhecimento de novas tecnologias a um vocabulário técnico, contudo apontando para fins puramente narrativos, as similaridades - ao menos superficiais - prosseguem em sua acumulação: a sátira "O embuste do balão", em meio ao léxico mais ou menos fiel aos princípios da aerodinâmica, é publicada em um periódico com o intuito expresso - e alcançado de burlar a opinião pública quanto à travessia do Atlântico a bordo de um balão de ar quente; em "Os fatos no caso do sr. Valdemar" ou "Um conto das montanhas escabrosas", os pensamentos pseudocientíficos do magnetismo e da hipnose, amplamente popularizados meio aos círculos sociais da Nova Inglaterra na primeira metade do século XIX, são utilizados como mote para narrativas insólitas. Poe faz uso dessas matérias e cria narrativas a partir de especulações que ignoram, dentro do âmbito ficcional, a validade dessas proposições.

Retornando ao propósito da discussão, a narrativa policial de Edgar Allan Poe não admite sua segregação em relação aos outros textos do autor. Quanto às denominações mais contemporâneas, embora seja conceitualmente difícil afirmar que "Os assassinatos na rua Morgue" se trata de um conto fantástico, é possível defender, seja pela origem, temática ou mesmo tom, que se trata de uma narrativa insólita. A história de detetive, por vezes apresentada pela sua grandeza racional, traz em seu subterrâneo uma agregação de 
temas que apontam em direções distintas. Recordando que Poe é um dos fundadores do gênero, temos que a narrativa policial, em sua gênese, já traz consigo a devida marca da subversão dos limites estruturais, de forma semelhante - empilhando as coincidências eternas - à própria postura quanto ao fantástico 7 .

Quanto a este tópico, ilustramos essa reflexão com uma passagem de outra obra que se comunica com o que debatemos nesta ocasião. Jorge Luis Borges, convertido em personagem em um daqueles momentos em que a literatura parece se revolver ao largo de anos para morder a própria cauda, afirma que Poe inventou a história de detetive, a anti-história de detetive e a paródia da história de detetive (VERÍSSIMO, 2009, p.119). As três possibilidades borgeanas poderiam magnetizar o leitor ou crítico a um jogo de correspondência com as três narrativas de Dupin, combinando da forma que fosse mais convencional. Mesmo se tratando do primeiro dos três, inclusive sendo introdutório quanto à própria elaboração da persona do detetive, "Os assassinatos na rua Morgue" é pouco convencional ao que se habitou a tomar como modelo para o gênero. Fora os inúmeros detalhes que trabalhamos ao longo do texto, um caso em que se descobre no final ter sido provocado por um orangotango atrapalhado, decapitando e desfigurando os cadáveres das vítimas, tende a provocar sobre o leitor um estranhamento não em relação à subversão das leis naturais, mas quanto à veracidade da ficção.

Quanto a Dupin, Edgar Allan Poe não parecia compreender muito bem o entusiasmo da crítica quanto à sua capacidade analítica. Em uma carta, o autor comenta:

7 No prefácio ao livro "Tales of the Grotesque and Arabesc", Poe já assinalava uma distinção desejada entre sua obra e o "estilo alemão", elaborado apenas para suscitar emoções ligeiras. (1978, p.473) 
You are right about the hair-splitting of my French friend [Dupin]: - that is all done for effect. These tales of ratiocination owe most of their popularity to being something in a new key. I do not mean to say they are not ingenious but people think they are more ingenious than they are - on account of their method and air of method ... Where is the ingenuity of unravelling a web which you yourself (the author) have woven for the express purpose of unravelling? The reader is made to confound the ingenuity of the supposititious Dupin with that of the writer of the story ${ }^{8}$ (POE Apud MABBOTT, 1978, p.521)

Quanto à engenhosidade da obra de arte, ou mesmo a de seu autor, cremos que nenhum comentário seja necessário. 0 acastelamento das camadas semânticas, a construção de um cenário que convoca um assassinato a ser cometido, a fuga sem rastros de dentro de um quarto fechado - longe da vaidade da suposição das motivações subjetivas que impulsionaram o autor a compor a obra -, são todos recursos expressos de um autor. Por outro lado, Dupin e sua cabeça dourada oscilam entre o engenho e a engenhoca - o mecanismo aprimorado, um legítimo objeto a ser visto nas exposições universais do século XIX, e o bibelô, o kitsch a ser apreciado como decoração para as salas de jantar. Suas ações, por outro lado, carecem de justificativa, fora o prazer. Na rua Morgue, os fins são puramente estéticos.

8 Você está certo sobre a sutileza de meu amigo francês [Dupin]: - tudo isso é pelo efeito. Esses contos de raciocínio devem a maior parte de sua popularidade por serem algo em um novo tom. Não quero dizer que não são engenhosos - mas as pessoas acreditam que são mais engenhosos do que são - por conta de seu método e de seu ar de método... Onde está a engenhosidade de desembaraçar uma teia que você mesmo (o autor) teceu com o objetivo expresso de desembaraçar? O leitor é levado a confundir a engenhosidade do farsante Dupin com aquela do escritor da história. (Tradução nossa) 


\section{REFERÊNCIAS}

COLUCCI, Luciana (2014). "Os crimes da Rua Morgue, O mistério de Marie Rogêt e A Carta furtada: marcas da espacialidade gótica na escritura detetivesca de E. A. Poe". Evidência, Araxá, 10(10), 143-154.

CORTÁZAR, Julio (2006). "Poe: o poeta, o narrador e o crítico". In: Valise de cronópio. Davi Arrigucci Jr. e João Alexandre Barbosa (Trad.). São Paulo: Perspectiva.

FISHER, Benjamin (2008). The Cambridge Introduction to Edgar Allan Poe. Cambridge: Cambridge University Press.

MABBOT, Thomas Olive (1978). The collected works of Edgar Allan Poe: volume II. Cambridge, London: The Belknap Press of Harvard University Press. In https:// www.eapoe.org/works/mabbott/tom2t000.htm Acesso em 08. Mai.2020.

POE, Edgar Allan (2019). "A filosofia da composição". In: O corvo. Paulo Henriques Britto (Org.). São Paulo: Companhia das Letras.

POE, Edgar Allan (2017). Edgar Allan Poe: medo clássico. Marcia Heloisa (Trad.). Rio de Janeiro: DarkSide Books.

PORTILHO, Carla (2009). Detetives ex-cêntricos: um estudo do romance policial produzido nas margens. (Tese - Doutorado). Instituto de Letras, Universidade Federal Fluminense, Niterói.

TODOROV, Tzvetan (2010). Introdução à literatura fantástica. Maria Clara Correa Castello (Trad.). São Paulo: Perspectiva.

VERÍSSIMO, Luis Fernando (2009). Borges e os orangotangos etenos. São Paulo: Companhia das Letras. 